\title{
RAZA Y NACIÓN EN LA POESÍA DE CRISTINA RODRÍGUEZ CABRAL
}

Luis A. Jiménez

\begin{abstract}
RESUMEN
Este estudio trata de la poesía de la autora afrouruguaya Cristina Rodríguez Cabral. Explora los conceptos de raza y nación dentro del complejo mosaico de la evolución histórica y literaria de la mujer del origen africano y sus descendientes en el Uruguay.

Palabras clave: poesía afrouruguaya, mujer, raza, nación, historia.
\end{abstract}

\begin{abstract}
This study deals with the poetry of Afro-Uruguayan autor Cristina Rodríguez Cabral. It explores the concepts of race and nation within the complex mosaic of the historical and literary evolution of woman of African origin and her descendents in Uruguay.

Key words: Afro-Uruguayan poetry, woman, race, nation, history.
\end{abstract}

Entre las figuras más sobresaliente de la poesía afrohispana del momento se encuentra Cristina Rodríguez Cabral (Montevideo, Uruguay 1959-). En efecto, se ha convertido en figura antológica importantísima en Hispanoamérica. Madre soltera, poeta, conferencista y profesora universitaria, también ha demostrado su curiosidad por la ciencia y ha ejercido como enfermera en su ciudad natal.

Recientemente, la escritora afra-uruguaya, prefijo acuñado por Miriam DeCostaWillis (1993: 204-16) ${ }^{1}$, ha publicado un volumen poético titulado Memoria \& Resistencia. Antología $(2004)^{2}$. Esta antología consta de once secciones que incorporan textos ya publicados en poemarios anteriores ${ }^{3}$. Para DeCosta-Willis, las primeras composiciones de Rodríguez Cabral se centran en el amor, los sentimientos íntimos y la experiencia de la mujer afrohispana. Agrega que las obras después de 1995 descubren su militancia social, el racismo y la pobreza del negro, lo mismo que su alienación cultural y física, y su identidad de mujer de descendencia africana (2003: 389).

Dr. Luis A. Jiménez. Catedrático Emérito del Florida Southern College. Especialista en la literatura de mujeres, el Caribe y el siglo XIX en Hispanoamérica.

Correo electrónico: LJIMENEZ@ut.edu

Recepción: 5-7-2006

Aprobación: 25-7-2006 
Este estudio explora los conceptos de raza y nación articulados al discurso poético de Rodríguez Cabral. En general, constituyen dos ingredientes inseparables y vitales, que todavía quedan por resolver en la ubicación de la escritora al complejo mosaico de la evolución histórica y literaria de la mujer negra en el Uruguay ${ }^{4}$. Más específicamente, ambos conceptos insertan a la mujer de origen africano a la diáspora afro-uruguaya y exaltan la rica herencia de sus antepasados (que constituye un porcentaje pequeño de la población) en el trayecto cultural del país. Como ha señalado Nancy Morejón en cierta ocasión, dicho proceso no puede aislar el texto de su contenido socio-histórico (en DeCosta- Willis 1995: 98). Por tanto, se asume la permanencia y la pertenencia de la mujer negra uruguaya fuera y dentro de la perspectiva eurocéntrica de la cultura dominante de la nación.

Sobre Rodríguez Cabral, Marvin A. Lewis ha señalado en su libro Afro-Uruguayan Literature. Post-Colonial Perspective que su "preocupación por la identidad y resistencia" prevalece insistentemente en la constancia temática de sus poemas (2003: 94). Tras analizar dos textos poéticos de la autora ("Monte-vi-deo" y "Memoria y Resistencia"), se refiere a su visible "contradiscurso" y concluye diciendo que la construcción del sujeto negro en América refleja la legitimidad de un discurso que promueve las circunstancias históricas que provocan el sentido de pérdida y abandono de la diáspora (2003: 103), en búsqueda de un rescate de la raza, la cultura y la nación uruguaya dentro del proceso discursivo de la escritura.

Más concretamente para nuestro enfoque, Lorna V. Williams sostiene que Rodríguez Cabral cuestiona los "modelos eurocéntricos de conocimiento", inesquivables en las "prácticas socio-culturales africanas" (1995a: 27-8). Añade la investigadora que la poesía de esta autora provee al lector con nuevas herramientas de lucha para una relectura inclusiva de la historia uruguaya, contaminada por el elitismo eurocéntrico excluyente. Al mismo tiempo, descarta las "diferencias categóricas" entre los descendientes de África y los de Europa (1995a: 28), y que se barajan en dos espacios controvertidos hasta el presente. A nuestro juicio, la construcción autóctona de la imagen racial en el Nuevo Mundo se presenta en la obra de Rodríguez Cabral de una forma globalizada con la intención latente de borrar fronteras prejuiciosas en su totalidad.

En relación con el anonimato de la publicación de la obra del negro en Uruguay, se debe subrayar como agregado aclaratorio que esta producción artística se ha mantenido tácitamente en la "oscuridad", y solo es accesible en las revistas afrouruguayas del país, según el criterio de Caroll Mills Young (1991: 72). En otras palabras, dicha obra completa nunca se ha dado a conocer al público ni ha sido incluida en el "sistema literario" de la nación, tal y como lo indica Young en el artículo sobre literatura afrouruguaya antes mencionado 5 .

Con respecto a lo dicho, Homi K. Bhabha expone que la doble escritura de la "diseminación" derridiana implica metafóricamente al pueblo como un todo, aparte de las diferencias culturales de este pueblo (1995: 139, 148). A nuestro modo de ver, dichas diferencias deben servir de encuentro entre las minorías, como en el ejemplo de la diáspora afrouruguaya en este estudio global sobre Rodríguez Cabral. En otra exposición crítica, Frantz Fanon sostiene que la práctica textual de lo típicamente "afro" es un intento por borrar el fetichismo contenido en los estereotipos raciales, lo que llama un "simulacro" o una "doblez" a lo largo de su libro Black Skins, White Masks (1991: 109-40). En esta obra el crítico cuestiona los efectos de la colonización eurocéntrica, bajo la presunción de una superioridad dogmatizante, racista y marginadora. Consciente o no, Rodríguez Cabral recoge la situación del sujeto colonizado y la condena en su empeño progresista por la ampliación de los parámetros sociales en el 
Uruguay. Al mismo tiempo, proclama la africanidad como una "parte seria de la ciudadanía" (Kubayanda 1982: 22).

Empecemos ahora con "De: noches sin luna, días con sol”, poema de fuertes matices autobiográficos. Pese a la doble antítesis obvia del título, la persona literaria con el optimismo que la caracteriza se identifica con nuestro continente y enfila hacia sus raíces ancestrales.

Desde una perspectiva transnacional, el poema abre diciendo: "Latina, / hispana, / sudamericana / con sangre africana latiendo en mis venas" (2004: 17). A un nivel más personal, lo que la poesía de Rodríguez Cabral busca es un deseo innato en su fase inicial, que cubra la armonía racial en la América Latina; y particularmente pretende subrayar el componente hispanonegroide. Esta primera estrofa de alto contenido trasatlántico porque abarca tres continentes, concluye con la declaración de la voz yoica que es "ante todo / un ser humano, una mujer negra" (2004: 17), lo que le brinda cierto sentido de permanencia y pertinencia a la vez. De hecho, captamos que el aplomo racial y la reclamación de "una mujer negra" se convierte en el centro discursivo del texto: la libera de la conocida noción de "subalterna" que propone Spivak cuando pregunta en su artículo: ¿puede el subalterno hablar? (194: 66-111). Cuando habla la voz lírica del poema en cuestión admite, rescata, reclama y se siente muy orgullosa de sus orígenes africanos 6 .

En términos de identidades múltiples (latina-hispana-sudamericana-africana), una vez establecida la hispanidad y, sobre todo, la negritud del sujeto femenino, la hablante realiza un bosquejo de su genealogía, breve por cierto, debido a las limitaciones espaciales que sujetan el discurso poético. Aclaremos que el término negritud, más que ideología, implica ontología. Paradójicamente, según René Depestre, formula el despertar de la autoestima y la confianza en el poder de un grupo social oprimido que la esclavitud ya había reducido a bestias de carga (1984: 251). En cuanto a la genealogía, al lidiar con el tema institucionaliza la familia en el discurso literario. Sin seguir una cronología precisa en el poema, después de enterarnos de que su abuela fue lavandera y su abuelo historiador, se alaba la figura paterna que "hablaba del racismo / y del deber de cada Negro / de mostrar, siempre de sí mismo, lo mejor" (2004: 17). Para Teresa Porzecanski, este racismo en el Uruguay al que alude la hablante es simplemente "un prejuicio social basado en una generalización infundada, no racional, construida sobre un estereotipo que expresa un grado de opresión (en Santos y Lorriaga s.f.: 41).

Como infatigable lectora de tantos libros, el retrato del abuelo ofrece una visión concisa del ciudadano letrado de la nación. Sin llegar a ser portador del discurso oficial y hegemónico del siglo XIX en el Uruguay, su función en el texto sirve de autoridad cultural y propagador de esta, incluso entre los vecinos del barrio que lo tomaban por loco. Resulta importante destacar que con la representación de este ente poético en la escritura, el aprendizaje del sujeto negro dignifica "su procedencia ancestral" y enorgullece "su acervo cultural" (2004: 17), como otorgante de conocimiento. De estos pronunciamientos se desprende que, tanto los orígenes como la cultura, suscitan y promueven la noción de que la raza puede y debe actuar como adelanto cognoscitivo e instructivo en el proceso de la historia de la nación.

Particularmente, conviene referirnos a la capital montevideana que vio "nacer, crecer, amar, sufrir, morir y resucitar" a Rodríguez Cabral, y que se hace presente en su poema "Montevi-deo" (2004: 117), entre otros. La ciudad se convierte en una especie de "patria chica". Sin embargo, "condena al exilio" a la poeta (2004: 117). No es de sorprender entonces que en la práctica textual defina, asiente y se apropie de su territorio, desde el nacimiento y el sufrimiento hasta la muerte, pasando por la resurrección del sujeto aún viviente en el discurso poético. 
Seguidamente, en "De: noches sin luna, días con sol", la hablante se remonta a los tatarabuelos para hacer hincapié en la esclavitud de Uruguay ${ }^{7}$. De los afrodescendientes, comenta que la tatarabuela fue esclava y que su hijo "sería la última generación esclava / en la familia / en el Uruguay. Luego..." (2004: 18). Entre puntos suspensivos, deja aclarado en un modo gráfico el motivo del aprendizaje del sujeto negro, ya que más adelante le obsequia al hijo su primer libro, que "sembró la primera flor" (2004: 18). Resurge en esta instancia lírica el deseo de la comunidad afrouruguaya por la lectura, el conocimiento y la superación autodidacta que se adquirían en aquel entonces mediante la operaciones textuales que eran accesibles por libros limitadísimos en las colonias americanas, y mucho más en este enclave sudamericano. La tatarabuela se proyecta inequívocamente en el poema con un espíritu valiente que "flameaba en su sangre / la bandera libertaria" (2004: 18). Apunta que serían liberados principalmente de la ignorancia. La metáfora de la "primera flor" fructifica en el jardín del abuelo, anheloso de su "compromiso genealógico" con el porvenir de la nación que hereda la nieta: Cristina Rodríguez Cabral.

En efecto, con la mención a la "bandera libertaria" se proyecta claramente el primer símbolo de la independencia del Uruguay, presupone no sólo la libertad del sector afrouruguayo, sino también la aceptación de lo que la hablante llama "nuestra africanidad" (2004: 18). Las alusiones patrióticas de la "bandera libertaria" conducen al "respeto" y el "sacrificio" de esta comunidad hacia la nación como significante ideal del discurso (Balibar 1991: 95, 104). La "primera flor", por otro lado, convertida en el jardín de los libros y sembrada por el abuelo, pasa a manos de la nieta, artesana de la escritura. La metáfora repetitiva repercute en la imagen de la madre al insistir en la fertilización de la tierra y su crecimiento progresivo. Es ahora que se da un paso del pasado al presente y resurge la voz yoica con la alusión a un "navegando libros". Cimienta otro eslabón instructivo que se articula y se añade a la cadena genealógica en el texto: "la promesa de la bisabuela" y "la sabiduría del abuelo", entre otros (2004: 19). Opinamos que el afán intenso por la instrucción da la impresión de una lectura en la que se establece cierto dialogismo textual entre los entes poéticos y se desplaza parejamente con ellos.

Acto seguido y aferrada a la sabiduría del abuelo, se apropia de Ogum, dios del panteón yoruba que transcultural y sincréticamente se vincula a San Antonio; y que el Babalao, sacerdote de Orúnmila o Ifá, asocia al hierro y a la guerra (Lanni s.f.: 50). En este ejemplo, Ogum, el herrero del mundo mítico de Dahomey transformado en Haití en divinidad guerrera, es del dueño de los metales. Es un loa (deidad) venerado en la santería cubana y la brasileña por ser emblema del machete y símbolo de la energía brutal. En el poema, el sujeto lírico se considera "Hija de Ogum / águila / mujer / guerrera" (2004: 19). En esta breve mención persevera la capacidad divina del sincretismo afrohispano (Droogers 1989: 7-25). En este segmento poético, el enfoque en la religión, como elemento transmisor de la continuidad socio-histórica y la herencia cultural, le sirve de arma de memoria y resistencia testimoniales. Así lo indica el título de la antología que se examina.

Esta poderosa imagen energética de Ogum tan palpable forma parte de las huellas identitarias africanas. Aparecen tempranamente en la obra de la poeta afrouruguaya Virginia Brindis de Salas (1908-1958), predecesora de Rodríguez Cabral. Brindis de Salas, por su parte, pregona al "Cristo negro" (Pregón de Marimorena 27) y se refiere a dioses afrouruguayos -Leybá, Dembolá, Uedó y Avidá- como fortaleza racial de la nación. De hecho, los referentes "Ogum" y "Cristo negro" en estas dos autoras adquieren cierto sincretismo oportuno para recoger una cosmovisión global de un país predominantemente católico. 
Poéticamente, la hablante de Memoria \& Resistencia traspasa estos poderes sobrenaturales a su hija Nzinga, "otra guerrera" en la obra, con la intención de "ser cada día mejor" (19). Como recalca Carole Boyce Davies en su artículo "Woman Is a Nation...," el sujeto femenino negro porta la sabiduría y el poder proverbial en contraposición con el estereotipado discurso dominante de la superioridad masculina (1995: 166, 185), falsificado en la cultura etnocéntrica. El corolario cognoscitivo promueve e instruye a la hija que "bebe a diario del bagaje cultural / ancestral / y genealógico" (19). Es conveniente destacar ahora cómo se perfila aquí el carácter didáctico del poema ante el espíritu progresista de la persona literaria que acude una vez más a sus raíces ancestrales desde su óptica transatlántica.

Según nos informa la propia Rodríguez Cabral en una nota al pie en el poema "De: Desde mi trinchera" (1993), Nzinga Nbandi (1582-1663) fue "reina y guerrera que creó una poderosa coalición de etnias en el reino del Congo (actual Angola) liderando la resistencia contra los portugueses en el siglo XVII" (1993: 69, subrayados agregados). El primer subrayado es de sumo interés para el lector puesto que Rodríguez Cabral se nombra en varias ocasiones como una "mujer rebelde", traspasando estos valores a su hija. Por esta razón, la consideramos la "mujer rebelde" de la poesía afrohispana actual. En cuanto al segundo, se integra de manera acusatoria al título de la antología poética: Memoria \& Resistencia.

Cabe añadir que Nzinga-hija, el personaje infantil que desfila en la poesía de Rodríguez Cabral e intersticio de la negritud palpitante, reaparece en "Encarando el exilio" (2004: 61), en "Nuestra mejor canción" (2004: 973) y en "A mi Nzinga simiente de tres meses" (2004: 79), entre otros poemas. Importa resaltar aquí también cómo el nombre enlaza la resistencia de la raza a la historia angolesa del siglo XVII. El símbolo que el personaje histórico angolés representa, manifiesta la necesidad de reconocimiento de ciertas cultura africanas en la poesía de la escritora uruguaya. Algo análogo ejecuta Rodríguez Cabral cuando incorpora minuciosamente su estirpe racial, la de su hija, sus antepasados y el resto del pueblo afrouruguayo al proceso histórico de la nación. En adelante, al nombrar a Nzinga crea una "cadena" (dígase eslabón) y ejecuta un "gesto ideológico de resistencia cultural", según el juicio de Lorna V. Williams (1995: 32).

Examinemos por un momento la frase "ser cada día mejor" en el poema (la cual, dicho sea de paso, es sumamente contestataria). El enunciado reta a la comunidad afrouruguaya a la superación personal mediante el conocimiento, siempre atribuible a la población eurocéntrica del Uruguay. La previa inclusión y el consecuente intento de homogeneidad cultural, con anterioridad relegada a espacios marginados, se transforma en un proceso colectivo (Bhabha 1995: 1-2) e incluye también al pueblo afrouruguayo. Por esta razón, se rechaza virtualmente el presunto principio de la pluralidad hegemónica blanca de la nación en escrutinio. La hablante se percata de que el colonizador ajeno forjó la falsa imagen de "la Madre Patria". Por consiguiente, ya se ha convencido que esta imagen acarrea "aquella que nos parió tan mal" ("500 años después" (2004: 85). Con el marcador “aquella”, se denuncia el poder opresor de España sobre la existencia de sujetos indefensos y marginados, a los que se ha procurado ofender y relegar, empleando cualquier motivo de excusa disponible.

Además de ser mujer negra de origen africano y con ansias de superación, se convierte en portavoz del mestizaje americano, lo que asienta una vez más la hibridez racial de esta poesía. El testimonio de la herencia negra se afirma con fuerza persuasiva: "Soy una negra uruguaya / parida en la América Mestiza / con sangre Africana / templando / el tambor de mis venas" (2004: 19). Se observa en este último verso que el énfasis metafórico radica en la 
"cultura del tambor", la cual es desarrollada ampliamente por Marvin A. Lewis en su libro ya mencionado (2003: 47-61).

El poema cierra con el mismo pronunciamiento de la partitura para dejar asentadas su raza y, particularmente, su esencia humana dentro y fuera de los confines de la nación donde nace. Por medio de la socorrida repetición en el texto, la voz de la mujer negra reclama su espacio en la construcción histórico-literaria del Uruguay con un "soy" vibrante que reafirma esta postura. El enunciado "Soy una negra uruguaya" es lo suficientemente sólido para fundir la identidad racial y nacional de la persona literaria. También cobra importancia textual el enlace entre tres culturas, al igual que la mención a África, reflejo innato de su anhelo de conectarse con este continente (Brathwaite 1996: 190).

Continuemos con "Montevideo: la Navidad que no pudo ser", poema que proclama el autoexilio, el tambor de la negritud uruguaya y la evolución histórica del Uruguay. A través de todo el texto, surge la metáfora de la "poesía sangrienta" que transparenta y solidifica los conceptos de raza y nación que se analizan. Como función testimonial de la herencia africana en el Uruguay, explica que esta "poesía negra" brota en cada "esquina rioplatense de mi ser" (2004: 40). En este texto leemos de "Diáspora de destierros" y del "corazón diaspórico" que traen a colación sueños nocturnos entre "Cuareim y Ansina" (2004: 40), este último considerado "el fundador de la literatura oriental y padre de la patria vieja" (Antón y Miraldi 1996: 11)

Al entroncar con la historia de la nación en el siglo XIX, no revela únicamente su condición individual, sino que colectiviza los hechos de su pueblo compartidos con la experiencia del pasado y del presente incierto. En este caso específico, la poeta actúa de intermediaria entre una voz letrada afrouruguaya del ayer (Ansina) y la concesión de autoría / autoridad que la escritura del texto le otorga: ese "crujir en cada palabra" (2004: 40), al sonido del tambor. Es más, con su atractiva armazón sonora (no olvidemos el tambor) y con la mención de Ansina, figura negra hegemónica del Uruguay, le ofrece legitimidad a la construcción del discurso poético.

Otro ejemplo significativo del vínculo entre raza y nación reaparece en "Afrodiáspora". La concepción diaspórica que se desprende del título del poema crea cierto sentido de identidad en constante transformación, pero sin llegar a la instalación del mito. Al comentar sobre este paradigma identitario, Jorge Ruffinelli anota con precisión crítica que la incursión por el retorno al África no es ontológico sino histórico, debido a la necesidad urgente de recobrar la identidad perdida. Por lo tanto, este deseo incesante parte del rechazo al hispanoafroide originado por el racismo, la explotación y la condición colonial (1985: 23). La aparente superioridad del colonizador blanco se permea no solamente en el Uruguay, sino también en el resto de las naciones de Hispanoamérica con raíces fuertemente africanas e indígenas.

A través del poema, la voz lírica se apoya en un "nosotros" familiar que intenta unificar al pueblo afrouruguayo, al igual que en el poema "Hoy más que nunca", que se inspira en la "creación del hombre nuevo / buscamos nuestras manos / y nos enlazamos / somos y existimos" (2004: 86-7). Al desmantelarse el "yo" poético a favor de la primera persona del plural, el cambio de voces en el discurso se presenta como la alegoría de una imagen total e inclusiva, dígase nacional. Más que un proceso cognoscitivo, el juego hermenéutico del pronombre le permite al lector captar la verdad histórica de la nación. La composición abre con la falta de suerte de los que "forjamos nuestra esperanza / y nuestra trinchera" (2004: 59). Digamos de pasada que en esta retórica de la diáspora se retienen lazos fuertes con el pasado histórico y con la nación que vio nacer a Rodríguez Cabral. 
Además del "nosotros" explícito en estos versos, resulta muy elocuente el empleo del adjetivo posesivo "nuestra". Esta operación lingüística conduce a recrear una escena bélica: "Somos pueblos de la resistencia" (2004: 59). Esta instancia discursiva no solo actúa como un acto de solidaridad, sino también como expresión de la condición marginada a la que se sujeta por lo general al afrohispano en este continente. La guerra racial que se desarrolla entre los "eternos combatientes" produce viajes "en nortes y sures / estes y oestes" (2004: 59). La dialéctica espacial en este enunciado recorre y ensancha globalmente territorios dentro y fuera del Uruguay para abarcar el resto de Hispanoamérica. Tras este espacio geográfico global, la hablante cambia de nuevo del parámetro lingüístico del "yo" al "nosotros". Detalla este proceso de inclusión de la siguiente forma: "Despegamos, / nos dispersamos / y nos volvimos a encontrar" (2004: 59). Este fragmento lírico alude a la dispersión de la diáspora afrohispana que logra un reencuentro con un "hoy y siempre / arrastrados por el mismo mar" (2004: 59). Es este desplazamiento físico y psíquico de la diáspora el que experimenta Rodríguez Cabral en los Estados Unidos, donde ejerce como profesora universitaria.

Concluimos este asedio crítico con "Cimarrones", poema que explica con aplomo poético el concepto de raza y nación ${ }^{9}$. La hablante lírica le echa una mirada al pasado, gesto con el que ve "tantos negros / qué alegría vernos tantos" (2004: 75). Pese al júbilo de estos versos, comprende que pertenece a lo que llama "minorías", grupo marginado que ha observado con detenimiento a través de la experiencia ontológica y de la escritura poética. Testimonia con gesto punzante y carnavalesco los espacios recordados:

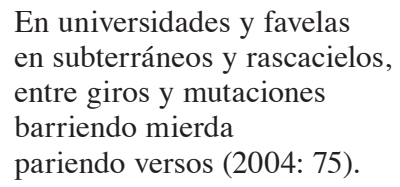

En otros poemas analizados, se conecta nuevamente con los ancestros, a quienes denomina "nuestros viejos" y que descansan dentro y fuera del "silencio de la noche larga" (2004: 75). Más adelante, en su empeño retador se apodera de la imagen del africano que habita su cuerpo y que recorre "la américa [sic] mestiza" (2004: 75). Resurge aquí otra indicación explícita de la hibridez prevaleciente en la poesía de Rodríguez Cabral. Metafóricamente, el africano en el texto se convierte en marco transnacional y plano referencial que convida a una lectura intrínseca de lo típicamente nacional en su período inicial: "el tejedor de la historia" (2004: 76).

Acto seguido, el africano se adueña de los versos de la poeta. Por medio de este sujeto, la hablante pondera al decir "planta sudor y fuerzas / en la bandera de nuestros pueblos" (2004: 76), reacción crítica y patriótica dentro del imaginario nacional que este emblema de la patria significa. Por asociación, se puede decir que "nuestros pueblos" se vinculan a nuestras naciones hispanoamericanas.

Prosiguiendo con la naturaleza híbrida que arroja el discurso, hermana al africano con el indio. Juntos, los dos sujetos de la enunciación alzan sus voces para romper "las fronteras impuestas" (2004: 76, subrayado agregado). Este subrayado ilustra un aspecto que confirma nuestro planteamiento inicial sobre la necesidad de establecer un modelo de globalización igualitario que borre el prejuicio racial a nivel transnacional. Dicho a la manera de la autora, en entrevista con Lorna V. Williams, la poesía "[e]s una forma de entrar en armonía con la gente, con el universo" (1995: 57). Por tanto, el sujeto que habla fraterniza con ellos mediante 
el adjetivo posesivos "nuestros". De nuevo, la voz yoica de otros poemas más personales fija el "nosotros" porque necesita incluirse en el proyecto histórico de las naciones hispanoamericanas: "mis hermanos indios / mis gemelos negros / somos la gran mayoría en pie" (2004: 76).

Al establecer el binomio minoría / mayoría en el poema, se apoya en la "gran" población indígena de Nuestra América, como dijera José Martí ideológicamente. El texto desemboca con la presencia del "africano cimarrón / en el camino del encuentro" (2004: 76). Este personaje histórico constituye una esencia vital de la identidad panamericana. Sin duda alguna, el proyecto literario de la poeta se encamina a promover una integración más plena del cimarrón. Refuerza al mismo tiempo la idea del papel de este héroe olvidado muchas veces dentro de la esfera histórica. Dicho de otro modo, lo coloca "en el camino del encuentro".

Si se compara esta composición con otra del poemario de Blas Jiménez, titulado Exigencias de un cimarrón (un sueño), captamos un pronunciamiento semejante sobre el término "mayoría". En la sección octava de este texto, el autor dominicano realiza un recordatorio del cimarrón bajo los efectos de una experiencia onírica entre paréntesis: "Hoy despierta Quisqueya / Y veo que soy mayoría / veo que soy tu mayoría (2004: 30, subrayado agregado) ${ }^{10}$. Ya en la contraportada de Memoria \& Resistencia se fijan afinidades literarias entre Rodríguez Cabral y Blas Jiménez. El escritor dominicano anota que en la autora de esta antología "el coraje Cimarrón [sic] afila el pensamiento y las palabras brotan para exigir espacios negados".

La alusión al susodicho cimarrón en ambos textos, además de su peculiaridad llamativa, apunta directamente hacia la expresión simbólica en la escritura de Cristina Rodríguez Cabral y Blas Jiménez. Su presencia altera el orden preestablecido por el amo colonizador y agente falso del discurso oficial. Recordemos que el cimarrón se escapa al bosque, al monte o la selva de Hispanoamérica en busca de su libertad debido a su espíritu rebelde, especialmente en el Caribe antillano; a veces, termina suicidándose en su resistencia activa debido a la memoria nefasta del colonizador opresor. Estos hechos inexcusables de la historia se inauguran en la cultura de plantación desde el siglo XVI. Una vez perfilado en el poema este escenario colonial, existe un "camino del encuentro" (2004: 76), la esperanza global que Cristina Rodríguez Cabral siempre contempla en el futuro.

En resumen, como se ha desarrollado en este asedio, en la poesía de Cristina Rodríguez Cabral observamos negociaciones viables del "yo" afrohispano y mujer con su herencia racial y nacional. Al retomar y apropiarse de la historia del Uruguay, la autora re-escribe y poetiza la nación desde una óptica afrocéntrica, con el propósito de asentar la identidad de la diáspora a la que pertenece y le da impulso a su discurso. Aún más, el "yo" poético que resuena en la obra se apoya a menudo en la herencia africana, pero no en tono nostálgico. Por el contrario, y de un modo asertivo, como ciudadana afronegroide de su país, reafirma el pasado cultural de sus antecesores y lo globaliza abiertamente en el didacticismo que su escritura propicia. Por último, al hacer de estos antepasados personajes líricos y sujetos vivientes de la historia, destaca los valores familiares que caracterizan a la comunidad afrohispana en general. Como bien dice Miriam DeCosta-Willis en su antología crítica, tanto Rodríguez Cabral como otras autoras afrohispanas son "hijas de la diáspora". 


\section{Notas}

1. La investigadora emplea el término para subrayar la escritura de mujeres que hablan español en el Caribe, Centroamérica y América del Sur (204).

2. Citamos de esta antología.

3. Remitimos al lector a obras citadas donde se incluye otro poemario publicado por Cristina Rodríguez Cabral

4. Véanse los artículos de Lorna L. Williams y Caroll Mills Young.

5. Para su estudio sobre Cristina Rodríguez Cabral, que también incluye a Maruja Pereira y Virginia Brindis de Salas, véase "The New Voices of Afro-Uruguay" (59-64).

6. Para Edward Kamou Brathwaite, el escritor hispanonegroide se centra en África como si fuera una "máscara" o una "señal", aunque sepa poco de este continente porque su afán es conectarse retóricamente con su pasado (1996: 190).

7. El proceso abolicionista nacional en el Uruguay comienza en 1813 y culmina en 1853 (Santos y Lorriaga s.f.: 24).

8. Joaquín Lenzina, conocido como Ansina, fue esclavo, sirviente y guerrero que luchó junto al general uruguayo José Gervasio Artigas por la independencia del país. Un paralelismo obvio entre las letras y las armas observamos en la relación entre el General Antonio Maceo y José Martí durante la Guerra del 95 en Cuba.

9. Rodríguez Cabral tradujo este poema al inglés y lo incluyó en Memoria \& resistencia (2004: 77-8).

10. Para Marvis A. Lewis, toda la poesía de Blas Jiménez se proyecta desde una óptica afrocéntrica (1991: 310). Lo mismo pudiera decirse del discurso poético de Cristina Rodríguez Cabral.

\section{Bibliografía}

Antón, Danielo y Armando Miraldi. 1996. Ansina me llaman y Ansina soy. Montevideo: Rosebud.

Balibar, Etienne e Inmanuel Wallerstein. 1991. Race, Nations, Class: Ambigous Identities. Chris Turner (trad.). London: Verso.

Bhabha, Homi K. 1995. The Location of Culture. London: Routledge.

Brathwaite, Edward Kaman. 1996. Roots. Ann Arbor: U of Michigan P.

DeCosta-Willis, Miriam. 1993. "Afra-Hispanic Writers and Feminist Discourse". NWSA Journal. 5 (Summer): 204-17. 
1995. "Orishas Circling Her House: Race As (Con)Text in Morejón's Poetic Discourse". En: Moving beyond Boundaries: Black Women's Diasporas. Carole Boyce Davies (ed.). Vol 2. New York: N. Y. UP.

2003. Daughters of the Diaspora. Kingston, Jamaica: Ian Randle Publishers.

Depreste, René. 1984. "Hello and Goodbye to Negritude". Africa in Latin America. Manuel Moreno Fraginals (ed.). New York: Holmes and meir Publishers, Inc. 251-72.

Droogers, André. 1989. "Syncretism: The Problem of Definition of the Problem”. Dialogue and Syncretism: An Interdisciplinary Approach. Jerald Gort et al. (eds.). Grand Rapids, MI: Erdmans, 7-25.

Fanon, Frantz. 1991. Black Skins, White Masks. London: Pluto P.

Jiménez, Blas R. 1987. Exigencias de un cimarrón (en sueños). Santo Domingo: Editora Taller.

Kubayanda, J. Bekunuru. 1982. "The Linguistic Core of Afro-Hispanic Poetry: An African Reading". Afro-Hispanic Review. (September): 21-26.

Lanni, Octavio. "Social Organization and Alienation”. Africa in Latin American. 38-57.

Lewis, Marvin A. 1991. "Contemporary Afro-Dominican Poetry: The Example of Blas R. Jiménez". Journal of the College Language Association 343: 301-16.

2003. Afro-Uruguayan Literature. Post-Colonial Perspectives. Lewisburg: Bucknell UP.

Porzecansi, Teresa y Beatriz Santos (comp.). 1994. Historias de vidas: negros en el Uruguay. Montevideo: Ediciones Populares para América Latina.

Rodríguez Cabral, Cristina. 1993. Desde Mi Trinchera. Montevideo: Ediciones Mundo Afro. 2002. Memoria \& Resistencia. Antología. Santo Domingo: Editora Manatí.

Rufinelli, Jorge. 1985. Poesía y descolonización. Viaje por la poesía de Nicolás Guillén. Oaxaca, México: Editorial Oasis.

Santos, Beatriz y Lorriaga, Nené. s.f. África en el Río de la Plata. Buenos Aires: Editorial Amerindia.

Spivak, Gayatri K. 1994. "Can the Subaltern Speak?” Colonial Discourse and Postcolonial Theory. Patrick Willimas y Laura Crisman (eds.). New York: Columbia UP. 66-111. 
Williams, Lorna V. 1995a. "Difference and Identity in the Poetry of Cristina Rodríguez Cabral". Afro-Hispanic Review. (Fall): 27-32.

1995b. "Entrevista con Cristina Rodríguez Cabral en Montevideo en julio de 1993". Afro-Hispanic Review. 14 (2-Fall): 57-63.

Young, Caroll Mills. 1991. "The Literary Tradition of Afro-Uruguay". Afro-Hispanic Review 10 (September): 72-77.

1995. “The New Voices in Afro-Uruguay”. Afro-Hispanic Review. 14 (1-Spring): 58-64. 
